\title{
DORSAL WRIST GANGLION; COMPARATIVE STUDY BETWEEN ASPIRAION PLUS STEROID INJECTION VERSUS SURGICAL EXCISION
}

1. (FCPS General Surgery) Senior Registrar General Surgery Ward

Hayatabad Medical Complex, Peshawar

2. MBBS

Junior Registrar

Hayatabad Medical Complex, Peshawar

3. Trainee Registrar

Hayatabad Medical Complex, Peshawar

4. (FCPS General Surgery) CMO

Institute of Kidney Disease Hayatabad Medical Complex, Peshawar

5. (FCPS General Surgery)

Medical Officer

DHQ, North Wazirastan

Correspondence Address:

Dr. Yousaf Jan

House no 89, street no 2, sector K5, Phase 3 Hayatabad Peshawar, Pakistan.

dr.yousaf.shinwari@gmail.com

Article received on:

12/12/2015

Accepted for publication:

08/01/2016

Received after proof reading:

08/01/2016

\section{INTRODUCTION}

Ganglions are the most common soft tissue lesions of the hand and wrist. It is filled with a thick jelly-like fluid. Ganglia can develop after local trauma to the tendon or joint, but usually has no reasons. ${ }^{1}$ The most common sites for ganglion are on the back of the hand $(60 \%-70 \%)$, at the wrist joint as well as on the palmar side of the wrist. $^{2}$ Women are more commonly affected than males and generally seen between second and fourth decades of life. Ganglions usually develop after repetitive trivial trauma to the capsular and ligamentous structures of the joint to produce hyaluronic acid by stimulated fibroblasts.

Ganglions contains high concentration of hyaluronic acid and other mucopolysaccharides. ${ }^{3}$ Patients usually consult medical treatment because of the pain, swelling or fear of a

\section{Dr. Yousaf Jan', Dr. Waqas², Dr. Shaukat Hussain ${ }^{3}$, Dr. Muhammad Shah, Dr. Ahmad Din ${ }^{5}$} Hayatabad Medical Complex, Peshawar. Period: June 2009 to December 2011. Methodology: After taking permission from ethical and research committee. Included patients were all adult of surgical excision. All the patients were followed for complete resolution of ganglion, complications of treatment and recurrence within one year. Follow up arranged at $7^{\text {th }}$ day, 1 , ( because of high success and low recurrence rate. As injection-aspiration treatm morbidity than surgery, it should be reserved for patients not consented for surgery.

Key words: Wrist ganglion, Methylprednisolone, Aspiration

Article Citation: Jan Y, Waqas, Hussain S, Shah M, Din A. Dorsal wrist ganglion; comparative study between aspiraion plus steroid injection versus surgical excision. Professional Med J 2016;23(3):246-250. DOI: 10.17957/TPMJ/16.3217

malignancy. ${ }^{4,5}$ Westbrook et al in patients found the following reasons for treatment: $36 \%$ about appearance, $28 \%$ about malignancy, $26 \%$ for pain, and $8 \%$ for abnormal function. ${ }^{6}$

Different treatment modalities have been tried for ganglions. These include watchful wait, reassurance, aspiration alone, aspiration with steroid injection, surgical excision and more recently arthroscopic ganglion resection. All these modalities have different advantages and disadvantages. ${ }^{7,8,9}$ Treatment with Seton insertion with or without aspiration has been tried by some surgeons. ${ }^{10}$ Indications for more aggressive treatment include pain, interference with activity, nerve compression and imminent ulceration. ${ }^{11}$

Aspiration has been reported to be effective in $20 \%-30 \%$ of the patients. ${ }^{5}$ Surgical excision 
is best reserved for patients with persistent symptomatic ganglions. ${ }^{5}$ After puncture and aspiration the recurrence rate is greater than $50 \%$ for cysts in most locations, but is less than $30 \%$ for cysts in the flexor tendon sheath. Surgical excision is effective, with a recurrence rate of only $5 \%$ if done by an experienced surgeon. After surgical excision; histopathologic confirmation of ganglion is usually not required. ${ }^{12}$

The objective of this study was to compare the effectiveness and complications rates for wrist ganglion between aspiration plus steroid injection versus surgical excision.

\section{MATERIALS AND METHODS}

This study was carried out in the Department of General Surgery Hayatabad Medical Complex, Peshawar, Pakistan during the period from June 2009 to December 2011 after approval from hospital ethical and research committee. Patients having recurrent and infected ganglia, bleeding disorders, diabetics, cancers and had previous treatment for ganglia were excluded. All adult patients of either gender with dorsal wrist ganglion were included in the study.

Ganglion diagnosis was made on history and clinical examination. After informed written consent the patients were distributed in two groups: Group ' $A$ ' included patients for aspiration and injection treatment, while Group ' $B$ ' included patients for surgical excision. The injection treatment was carried out in out-patient clinic using aseptic technique. After cleaning and local anesthetic $1 \%$ lignocaine infiltration, the ganglion was first aspirated with $16 \mathrm{G}$ intravenous cannula and then 40mg methylprednisolone was injected using the same cannula port once the swelling had completely aspirated and then dressed with crepe bandage for 3 days. In the surgical excision group, similar standard aseptic precautions were followed and ganglion was completely excised by senior consultant in operating theatre under local anesthesia. Skin was closed with prolene $2 / 0$ sutures and wound was dressed with crepe bandage and stitches were removed after 5-7 days.
Patients were followed up to one year at $7^{\text {th }}$ day, $1,3,6$ and 12 months after treatment and the outcome measure were complete resolution of ganglion, complications and recurrence within one year. Treatment was considered successful with complete disappearance of the cyst at final visit and failure when recurrence occurred. Statistical data was analyzed using SPSS version 10 software.

\section{RESULTS}

Our study included total of 80 patients. There were 52 (65\%) female and 28 (35\%) male. The mean age was $26.37 \pm 5.62$ years. In 47 (58.8\%) patients the right wrist was involved and 33 (41.2\%) had left wrist ganglions. Out of 80 patients, 40 were treated in group A and 40 in group B. Swelling was a common presentation in all the patients, while pain and discomfort in $42(52.5 \%)$, cosmetic $68(85 \%)$ and fear of tumor in $19(23.8 \%)$ respectively.

In group $A$, complete resolution of ganglion achieved in $25(62.5 \%)$ patients at one month follow up. After second steroid injection at one month the remaining $15(37.5 \%)$ cases completely resolved at 3 month follow up. So at one year follow up, $30(75 \%)$ cases completely resolved with recurrence rate of $10(25 \%)$ out of 40 cases. So the overall success rate was $75 \%$ at one year. In group $\mathrm{B}$, the complete resolution was achieved in all patients at one and three months follow up. At sixth month and one year only $2(5 \%)$ patients had recurrence and success rate of $38(95 \%)$ at the end of one year follow up (Table-I).

In group A, mild pain was reported by 28 (70\%) patients treated with oral analgesics and reassurance. Only 4 (10\%) patients had moderate to severe pain postoperatively which necessitate intravenous pain killers. In the surgical excision group, almost all patients experienced mild to moderate postoperative pain which necessitated oral analgesics and in $4(10 \%)$ patients the pain persists for two weeks postoperatively. In group $A$, no patients had wound hematoma and one patient $(2.5 \%)$ had wound infection treated successfully with oral antibiotics. In group B, 3 
patients $(7.5 \%)$ developed wound hematoma and $2(5 \%)$ wound infections, both were treated with conservative measures successfully. Two patients in group B developed ugly scars.

\begin{tabular}{|c|c|c|}
\hline & $\begin{array}{l}\text { Success rate } \\
\text { of aspiration } \\
\text { and injection }\end{array}$ & $\begin{array}{l}\text { Success rate } \\
\text { of surgical } \\
\text { excision }\end{array}$ \\
\hline Present study & $75 \%$ & $95 \%$ \\
\hline Latif Ansar ${ }^{15}$ & $81 \%$ & $93 \%$ \\
\hline Bittner et $a^{26}$ & $66 \%$ & $97 \%$ \\
\hline Limphayan et al ${ }^{19}$ & 38.4 & 81.8 \\
\hline Khan PS ${ }^{21}$ & $61.1 \%$ & $94.4 \%$ \\
\hline Khan $F^{22}$ & $44 \%$ & $98 \%$ \\
\hline Humail SM ${ }^{20}$ & $57 \%$ & $76 \%$ \\
\hline
\end{tabular}

Table-l. Comparison of findings in different studies

\section{DISCUSSION}

Ganglia may cause pain and discomfort. Because of benign nature and in up to $50 \%$ cases of spontaneous resolution, non-surgical treatment options including simple observation, finger pressure, aspiration, injection of steroid, hyaluronidase, or sclerosing solution are usually advised initially for this lesion.,13 Treatment is usually required to patients with symptomatic ganglia.

In our study females predominates males as also shown in their studies by Saaiq $\mathrm{M}$,et $\mathrm{al}^{14}$ and Ansar et al. ${ }^{15}$ Right side was more involved than left side as also shown in their studies by Saaiq $\mathrm{M}$, et $\mathrm{al}^{14}$ and Oztürk K, et al. ${ }^{16}$

In 1976, Angelides and Wallace ${ }^{17}$ introduced the techniques of excising the whole ganglion to reduce the recurrence rate. It is now considered to be the most effective technique. Varley et al. in a randomized controlled trial concluded that additional injection of steroid is of no benefit and can leads to subcutaneous fat atrophy and skin de-pigmentation. ${ }^{18}$

In our study we observed a relatively higher recurrence with aspiration and injection (25\%) than surgical excision (5\%) and a success rate of $75 \%$ and $95 \%$ in aspiration plus injection and surgical excision group. In his study, Limphayan, et $\mathrm{al}^{19}$, reported the success rate of $38.4 \%$ by aspiration combined with methyl prednisolone acetate injection as compared to $81.8 \%$ with surgical excision of wrist ganglions, comparable to our own study. Humail SM, et $\mathrm{al}^{20}$ reported that the recurrence rate was $43 \%$ in aspiration and steroid injection and $24 \%$ in surgical excision for treatment of dorsal wrist ganglions, comparable with low recurrence rate of surgery in our study. Surgical excision had better success rate in the treatment of ganglions irrespective of the site.

In a study by Latif $A$, et $\mathrm{al}^{15}$, a success rate of $81 \%$ and $93 \%$ was achieved in aspiration plus steroid group versus surgical excision group, comparable to our own study of $75 \%$ and $95 \%$ success rate in aspiration plus injection versus surgical group. In another study ${ }^{21}$, the success rate of surgery was $94.4 \%$ and that of aspiration with steroid injection plus wrist immobilisation was $61.1 \%$, showing that surgery was the most successful form of treatment when considering the cure rate of dorsal wrist ganglion, as also shown in our current study. Our study is also comparable to a study conducted by Khan $\mathrm{F}$ et $\mathrm{al}^{22}$, showing success rates of $44 \%$ in injection treatment and $98 \%$ in surgical cases. Varley, et $\mathrm{al}^{18}$ found a $67 \%$ recurrence rate after aspiration with or without corticosteroid injection.

In our study more morbidity was seen in surgical excision group than aspiration plus injection group as also shown in his study by Saaiq $M$, et al. ${ }^{14}$ In group B all patients (100\%) had mild to moderate postoperative pain as compared to only $4(10 \%)$ patients in group $A$. In group $A$ no patient developed post aspiration wound hematoma as compared to $3(7.5 \%)$ patients in group B treated conservatively with aspiration and compression bandage successfully. Similarly two patients $(5 \%)$ in group $B$ had wound infections as compared to one (2.5\%) in group A. In Dias and Buch's cohort study ${ }^{9}$, surgery (20\%) had a higher complication rate compared with aspiration (5\%) or reassurance as also shown in our study. Since surgical excision usually has more postoperative morbidity, various newer techniques have been introduced to improve upon the results of surgery with low morbidity. So arthroscopic resection is 
a reasonable new alternative to open excision because of less postoperative morbidity and a better cosmetic result. 23,24

\section{CONCLUSION}

Surgical excision is superior to injection-aspiration method for dorsal wrist ganglion treatment because of high success and low recurrence rate. As injection-aspiration treatment has low morbidity than surgery, it should be reserved for patients not consented for surgery.

Copyright(C) 08 Jan, 2016.

\section{REFERENCES}

1. Ahn JH, Choy WA, Kim HA. Operative treatment for Ganglion Cysts of the Foot and Ankle. J Foot Ankle Surg 2010; 49: 442-5.

2. Memon F, Abbas R, Khan MA, Quraishy MS. Aspiration combined with seton insertion for treatment of wrist ganglions. J SurgPak 2007; 3: 121-3.

3. Minotti P, Taras JS. Ganglion cysts of the wrist. J Am SocSurg Hand. 2002; 2(2): 102-107.

4. James H, Calandruccio, Mark T, Jobe. Tumors and timorous conditions of the hand in: Campbell's operative orthopaedics. $11^{\text {th }}$ ed Mosby 2008: 43304331.

5. Edward A. Athanasian. Bone and soft tissue tumors in: Scott W Wolf, Robert N Hotchkiss, William C Pederson, Scott H Kozin, Green's Operative Hand Surgery. Vol. 2, Elsevier Churchill Livingstone, 2011: 2150-2156.

6. Westbrook AP, Stephen AB, Oni J, Davis TR. Ganglion: the patient's perception. J Hand Surg (Br) 2000; 25:566-567.

7. Gude W, Morelli V. Ganglion cysts of the wrist: pathophysiology, clinical picture, and management. Curr Rev Musculoskelet Med 2008; 1: 205-11.

8. Burke FD, Melikyan EY, Bradley MJ. Primary care referral protocol for wrist ganglia. Postgrad Med $\mathrm{J}$ 2003; 79:329-31.

9. Dias JJ, Buch K. Palmar wrist ganglion: does intervention improve outcome. A prospective study of the natural history and patient reported treatment outcomes. J Hand Surg 2003; 28:172-6.

10. Afridi SP. Use of seton in ganglions of the wrist. J Surg Pak 2006; 11: 121-3.
11. Jebson PJL, Spencer EE. Flexor Tendon Sheath Ganglions: Results of Surgical Excision. Hand 2007; 2: 94-100.

12. Jose J, Silverman E, Kaplan L. Symptomatic Ganglion Cyst of the Popliteus Tendon Treated With Ultrasound-Guided Aspiration and Steroid Injection: A Case Report. Sports Health 2011; 3: 393-5.

13. Singhal R, Angmo N, Gupta S, Kumar V, Mehtani A. Ganglion cysts of the wrist: a prospective study of a simple outpatient management. Acta Orthop Belg 2005; 71(5):528-534.

14. Saaiq M, Din HU, Zaib S, Ahmad S, Ali M. Dorsal wrist ganglions: Is aspiration and triamcinolone injection superior superior to surgical excision? Ann. Pak. Inst. Med. Sci. 2012; 8(2): 93-95.

15. Latif $A$, Ansar A, Butt MQ. Treatment of ganglions; a five years experience. JPMA 2014; 64(11): 1278-81.

16. Oztürk K, Esenyel CZ, Demir BB, Sönmez MM, Kara AN. Occult scapholunate ganglion in patients with dorsoradial wrist pain. Acta Orthop Traumatol Turc 2007; 41: 349-54.

17. Angelides AC, Wallace PF. The dorsal ganglion of the wrist: Its pathogenesis gross and microscopic anatomy, and surgical treatment, Journal of Hand Surgery. 1976; vol.1,no.3, 228-235.

18. Varley GW, Needoff M, Davis, Clay NR. "Conservative management of wrist ganglia: aspiration versus steroid infiltration,"Journal of Hand Surgery: 1997; European Volume, vol.22, no.5, 636-637.

19. Limpaphayom N, Wilairatana V. Randomized controlled trial between surgery and aspiration combined with methylprednisolone acetate injection plus wrist immobilization in the treatment of dorsal carpal ganglion. J Med Assoc Thai 2004; 87(12):1513-1517.

20. Humail SM, Amidi AR, Naeem-Ul-Haq S, Mustafa KG. Comparative study of two methods for treatment dorsal wrist ganglion. J Pak Orthopaedic Assoc 2010; 22(1):53-56.

21. Khan PS, Hayat $H$. Surgical excision versus aspiration combined with intralesional triamcinolone acetonide injection plus wrist immobilization therapy in the treatment of dorsal wrist ganglion; a randomized controlled trial. J Hand Microsurg 2011; 3: 55-7.

22. Khan F, Butt KA, Hussain FN. Treatment of dorsal carpal ganglion; a comparative study between surgical excision and aspiration followed by steroid injection. J Pak Orthopedic Assoc 2011; 23: 7-12. 
23. Edwards SG, Johansen JA. Prospective outcomes and associations of wrist ganglion cysts resected arthroscopically. J Hand Surg Am 2009; 34(3):395-400.
24. Rocchi L, Canal A, Fanfani F, Catalano F. Articular ganglia of the volar aspect of the wrist: arthroscopic resection compared with open excision. A prospective randomised study. Scand J Plast Reconstr Surg Hand Surg 2008; 42(5):253-9.

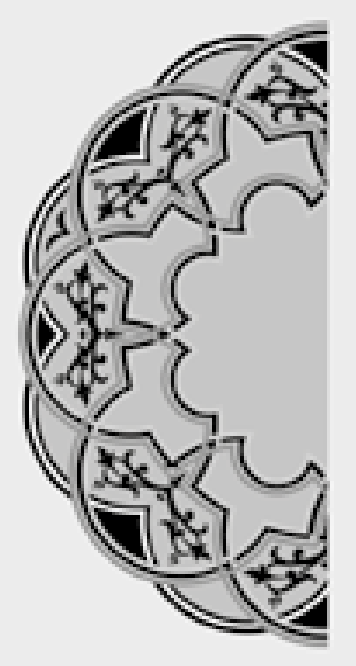

\title{
"Never approach a bull from the front, A horse from the rear or an idiot from any direction."
}

\author{
Unknown
}

\begin{tabular}{|c|c|c|c|}
\hline \multicolumn{4}{|c|}{ AUTHORSHIP AND CONTRIBUTION DECLARATION } \\
\hline Sr. \# & Author-s Full Name & Contribution to the paper & Author $=$ s Signature \\
\hline 1 & & $\begin{array}{l}\text { Collection data, } \\
\text { Interpretation of data }\end{array}$ & \\
\hline 2 & Dr. Waqas & Conception + Design & \\
\hline 3 & Dr. Shaukat Hussain & Collection of data & \\
\hline 4 & Dr. Muhammad Shah & Drafting of the article & \\
\hline 5 & Dr. Ahmad Din & Analysis of data & \\
\hline
\end{tabular}

